VS19-P03

\section{Two polymorphs of a fibrous titanium oxophosphate as repository for active metal cations}

\author{
Santiago Garcia-Granda ${ }^{1}$ \\ 1. Department of Physical and Analytical Chemistry, University of \\ Oviedo-CINN., Oviedo - 33006, Spain \\ email:sgg@uniovi.es
}

The pioneering studies on crystalline titanium phosphates were conducted by the Alberti Lab in the University of Perugia (Italy) and emerged in the wake of the work of the Clearfield Lab (USA) on zirconium phosphates, not to mention the contributions from the Soviet school, especially the Chernukov Lab in Nizhni Nóvgorod (Russia). In this context, our group at the University of Oviedo (Spain) published its first articles on this topic at the beginning of the 1980s. In the last decades, a great variety of metal phosphates has been synthesized and characterized. These compounds exhibit a multitude of fascinating structures and the dimensionality of their inorganic framework encompasses one-dimensional chain or ladder structures, two-dimensional layers and three-dimensional structures possessing channels of different sizes [1]. Two $\mathrm{Ti}_{2} \mathrm{O}\left(\mathrm{PO}_{4}\right)_{2} \cdot 2 \mathrm{H}_{2} \mathrm{O} 3 \mathrm{D}$-polymorphs $(r$-TiP and $\pi$-TiP) were prepared hydrothermally [2], and the crystal structure of two polymorphs were solved $a b$ initio from synchrotron X-ray powder diffraction data. The topology of two fibrous materials consists of a Ti/P/O framework enclosing two different linear channels parallel to the direction of fibers growth, both containing water molecules coordinated to only one of two octahedral-coordinated independent titanium atoms. Since the synthesis of $r$-TiP and $\pi$-TiP, and although this compound has been the subject of much attention and studies, our renewed interest in this material broke out as a result of its measurable thermally activated nitrogen-adsorption [3]. This behavior constitutes the first example of nitrogen-fixation by an inorganic material at above-ambient temperature. Despite of their neutral network, these compounds exhibit a surprising ability for the intra-crystalline incorporation of metal cations into their structural channels maintaining its fibrous topology. Here, we report the synthesis and characterization of metal-based materials with potential use as photoluminescent devices (europium), bioactive systems (silver), or anodes for metal-ion batteries (alkali metals).

Acknowledgments. This work was financially supported by Spanish MINECO (MAT2016-78155-C2-1-R).

References:

[1] Z. Amghouz, B. Ramajo, S.A. Khainakov, I. da Silva, G.R.

Castro, J.R. García, S. García-Granda, Dimensionality changes in the solid phase at room temperature: $2 \mathrm{D} \rightarrow 1 \mathrm{D} \rightarrow 3 \mathrm{D}$ evolution induced by ammonia sorption-desorption on zinc phosphates, Chem. Commun. 50, 6729-32 (2014).

[2] A.I. Bortun, S.A. Khainakov, L.N. Bortun, D.M. Poojary, J. Rodríguez, J.R. García, A. Clearfield, Synthesis and characterization of two novel fibrous titanium phosphates Ti2O(PO4)2 $2 \mathrm{H} 2 \mathrm{O}$, Chem Mater., 9, 1805-11 (1997).

[3] J. García-Glez, Z. Amghouz, I. da Silva, C.O. Ania, J.B. Parra,

C. Trobajo, S. García-Granda, The ability of a fibrous titanium oxophosphate for nitrogen-adsorption above room temperature, Chem Commun. 53, 2249-51 (2017).

Keywords: Titanium-phosphate, photoluminescence, metal-ionbatteries.
MS19-P04

\section{Structural, dielectric and photoelectrochemical properties of new lead-free ceramics of composition $\mathrm{Ba}_{\mathbf{0 . 9 2 5}} \mathrm{Bi}_{0.05}\left(\mathrm{Ti}_{\mathbf{0 . 9 5 - \mathrm { x }}} \mathrm{Zr}_{\mathrm{x}}\right) \mathrm{Sn}_{\mathbf{0 . 0 5}} \mathrm{O}_{3}$}

Kamel Taïbi ${ }^{1}$, Nesrine Taïbi-Haddadou ${ }^{1}$, Abdelilah Lahmar ${ }^{2}$, Gharib Rekhila $^{3}$, Mohamed Trari ${ }^{3}$

1. Crystallography and Thermodynamics Laboratory, Faculty of Chemistry USTHB, Algiers, Algeria

2. Physical Laboratory of Condensed Matter, Picardie University, Amiens, France

3. Laboratory of Storage and Valorization of Renewable Energies, Faculty of Chemistry USTHB, Algiers, Algeria

email: kameltaibi.dz@gmail.com

Classical ferroelectrics and relaxors are two distinct classes of materials [1]. Among these, BaTiO3 is the best-known prototype of classical ferroelectric materials characterized by three phase transitions: rhombohedral-orthorhombic-tetragonal-cubic. The ferroelectric (tetragonal) -paraelectric (cubic) phase transition occurs at $120{ }^{\circ} \mathrm{C}$ and the orthorhombic-tetragonal transition occurs at low temperature $\left(\sim 5{ }^{\circ} \mathrm{C}\right)$. The improvement of the properties of $\mathrm{BaTiO} 3$ has been the subject of considerable efforts for several years. The abundant literature has shown that many substitutions have been tried in ( $\mathrm{Ti}$ and/or $\mathrm{Ba}$ ) sites. Some of these substitutions give rise to a particular dielectric behavior known as relaxor. In addition to the usual applications of ferroelectric materials, relaxors are used in the fabrication of dielectrics for capacitors and actuators [2]. Unfortunately, these materials are based on lead which is harmful to the environment. As a result, research is directed towards environmentally friendly applications using leadfree materials as alternatives. It is in this context that the present study was conducted. We have initially elaborated new ceramics of formula $\mathrm{Ba} 0.925 \mathrm{Bi} 0.05$ (Ti0.95-xZrx) $\mathrm{Sn} 0.05 \mathrm{O} 3$ and symbolized by the term BBiTZxS $(\mathrm{x}=0.05$, $0.15,0.20 ; 25,0.30)$. After that, we studied the evolution of the structure and the dielectric properties as a function of $\mathrm{Zr}$ composition. The characterizations were performed by $\mathrm{X}$-ray Diffraction, Raman Spectroscopy and dielectric measurements as a function of temperature. The results show a classical ferroelectric behavior at low concentrations of $\mathrm{Zr}$ which turns into a relaxor when the $\mathrm{Zr}$ content increases. On the other hand, preliminary photoelectrochemical investigations showed appropriate position of the energetic band of these materials which is very interest for photocatalysis applications while respecting the environment.

References:

[1] Cross, L. E, (1994) Ferroelectrics 151, 305-320.

[2] Uchino, K, (1994) Ferroelectrics 151, 321-330

Keywords: Lead-free, Ferroelectric relaxor, Photoelectrochemical 